\title{
O bilinguismo nas práticas de ensino, pesquisa e extensão da UNILA: um diagnóstico, em números, de sua realidade linguística
}

\author{
El bilingüismo en las prácticas de enseñanza, investigación y extensión de \\ UNILA: un diagnóstico, en números, de su realidad lingüística
The bilingualism settled on teaching, research and extension practices of UNILA: a diagnosis, in numbers, of its language reality

\author{
Marina Magalhães Moreira ${ }^{1}$ \\ Bruna Macedo de Oliveira ${ }^{2}$
}

\begin{abstract}
Resumo
A Universidade Federal da Integração Latino-Americana (UNILA) é uma universidade brasileira assentada no compromisso com o desenvolvimento das sociedades da América Latina, que além de ser bilíngue (portuguêsespanhol), propõe a participação de estudantes e docentes oriundos de diversas partes do Brasil e demais países latino-americanos. O presente trabalho surgiu do projeto de pesquisa "Políticas e Realidades Linguísticas na UNILA", com a pretensão de elucidar como se manifesta o bilinguismo enquanto princípio filosóficometodológico desta universidade em suas práticas de ensino, pesquisa e extensão. Para tanto, analisamos quantitativamente as bibliografias dos cursos de graduação, mestrado e especialização, bem como os projetos de pesquisa e de extensão. Partimos do conceito de "política linguística de facto" proposto por Shohamy (2006), a fim estruturar uma análise calcada na realidade institucional observada por meio de informações e documentos oficiais.
\end{abstract}

Palavras-Chave: Bilinguismo; Multilinguismo; Política Linguística; Realidade Linguística; UNILA

\section{Resumen}

La Universidad Federal de Integración Latinoamericana (UNILA) es una universidad brasileña asentada en el compromiso con el desarrollo de las sociedades de América Latina, que además de ser bilingüe (portuguésespañol), propone la participación de estudiantes y docentes originarios de diversas partes de Brasil y de los demás países latinoamericanos. El presente trabajo se origina en el proyecto de investigación "Políticas e Realidades Linguísticas na UNILA", y tiene como objetivo aclarar cómo se presenta el bilingüismo en tanto principio filosófico-metodológico de esta universidad en sus prácticas de enseñanza, investigación y extensión. Para tanto, analizamos cuantitativamente las bibliografías de las carreras de grado, maestría y especialización, así como los proyectos de investigación y extensión. Partimos del concepto de "política lingüística de facto" propuesto por Shohamy (2006), con el fin de estructurar un análisis calcado en la realidad institucional observada por medio de informaciones y documentos oficiales.

Palabras claves: Bilingüismo;Multilingüismo; Política Lingüística; Realidad Lingüística; UNILA

\footnotetext{
${ }^{1}$ (Graduanda em Ciência Política e Sociologia - Sociedade, Estado e Política na América Latina; Universidade Federal da Integração Latino-Americana - UNILA; Foz do Iguaçu, Paraná, Brasil; marina.magaa@ gmail.com)

2 (Mestre em Letras pela Universidade de São Paulo; docente de Língua Espanhola Adicional no Ciclo Comum de Estudos da Universidade Federal da Integração Latino-Americana - UNILA; Foz do Iguaçu, Paraná, Brasil; bruna.oliveira@unila.edu.br)

Trabalho apresentado no I Seminário Latino-Americano de Estudos em Cultura - SEMLACult, Foz do Iguaçu/PR, Brasil, 2017.
} 


\begin{abstract}
The Federal University of Latin American Integration (UNILA) is a Brazilian university settled on the commitment with the development of the Latin American communities, which beyond being bilingual (portuguese-spanish), it proposes the participation of students and teachers from all over Brazil and the others Latin American countries. This study is born from the project "Politicas e Realidades Linguísticas na UNILA", and aims to elucidate how the bilingualism is presented as a filosofical and methodological principle of this university thru teaching, research and extension practices. For this purpose, we will analyse quantitatively the bibliography of all the graduation and post-graduation courses, as well the research and extension projects. We will be based on the concept of "facto language policy" proposed by Shohamy (2006), in order to do an analysis settled on the institutional reality showed by oficial informations and documents.
\end{abstract}

Keywords: Bilingualism; Multilingualism; Language Policy; Language Reality; UNILA.

\title{
1. Introdução
}

A Universidade Federal da Integração Latino-Americana (UNILA) é uma universidade brasileira situada em Foz do Iguaçu - Paraná, criada pela Lei no 12.189 de 12 de janeiro de 2010. Segundo o Plano de Desenvolvimento Institucional (PDI 2013-2017) da UNILA, sua missão é contribuir para a "integração solidária e a construção de sociedades mais justas na América Latina e Caribe por meio da geração, transmissão, difusão e aplicação de conhecimentos produzidos pela indissociabilidade de ensino, pesquisa e extensão" (p. 7). Para tanto, estabeleceram-se como princípios filosóficos e metodológicos a interculturalidade, o bilinguismo (português e espanhol) e o multilinguismo, a integração solidária e a gestão democrática.

Além disso, a vocação internacional da UNILA prevê a participação de estudantes e docentes oriundos de todo o Brasil e dos demais países latino-americanos. Por isso é possível afirmar que nesta universidade coexiste uma pluralidade linguística, cultural e social que toma corpo em todos os âmbitos da instituição.

Por ser uma universidade jovem ainda em processo de institucionalização de muitas de suas instâncias, faz-se extremamente importante a colaboração da comunidade acadêmica em seu processo de implementação, a partir da fiscalização e participação nas tomadas de decisões. Portanto, o bilinguismo e o multilinguismo, enquanto pilares desta universidade, devem ser alguns dos alvos deste olhar crítico.

Uma universidade conformada por um corpo discente tão heterogêneo, contando com aproximadamente $35 \%$ de estudantes que não têm o português como primeira língua, deve ter suas práticas linguísticas estudadas com afinco, a fim de dirimir as possíveis barreiras estabelecidas nos mais diversos âmbitos devido à diversidade linguística.

Alguns estudos prévios indicaram, apesar desta realidade plural, uma série de dificuldades na efetivação da proposta bilíngue da UNILA, reconhecendo falhas e 
contradições ao longo de seu processo. Oliveira (2016), em sua apresentação no $3^{\circ}$ Congresso Internacional de Professores de Línguas Oficiais do Mercosul, denominada "Las políticas de gestión de las lenguas en UNILA: un estudio de caso a partir de los documentos oficiales de la institución", identificou certa omissão por parte da instituição em definir o conceito de "bilinguismo" em seus documentos oficiais, além da existência de um trânsito entre as ideias - tampouco devidamente definidas - de "educação bilíngue", “ensino bilíngue" e "universidade bilíngue" ao longo desses documentos. Também preocupada com o que a UNILA percebe como "bilinguismo", Carvalho (2012, p. 141) identificou a predominância da língua portuguesa nos diversos espaços da universidade e atribuiu a esta o "gozo de maior status" diante das outras línguas presentes neste contexto.

Seguindo essa linha, a presente pesquisa se dedica a contribuir para a realização de para um diagnóstico da realidade linguística da UNILA, através da análise de suas políticas linguísticas. Para isso, tivemos como respaldo teórico o modelo analítico proposto por Shohamy (2006 apud BERGER, 2015, p. 57-8), no qual a autora identifica o conceito de "mecanismos políticos (policy devices)", descrito por Berger (2015, p. 57-8) como aqueles que:

\footnotetext{
se situam entre as ideologias e as práticas e através dos quais as políticas são implementadas, incorporando, assim, as agendas ocultas. A linguista argumenta que mesmo as políticas explícitas que sustentam o multi/plurilinguismo nem sempre refletem as políticas de facto, servindo somente como declarações e intenções, mas que não saem do papel. Desse modo, ela entende que as políticas de facto são determinadas por uma série de mecanismos que, por vezes, perpetuam uma Política Linguística vigente e contribuem para que ideologias difundam-se de forma homogênea e hegemônica (SHOHAMY, 2006, p. 52-53). Tais mecanismos incluem leis, documentos normativos, políticas linguístico-educacionais, exames de proficiência, a disposição das línguas no espaço público, ideologias, propaganda e coerção.
}

O modelo analítico de Shohamy é central neste artigo, que compõe uma das faces de análise de uma pesquisa mais ampla intitulada "Políticas e Realidades Linguísticas na UNILA", sob coordenação das professoras Bruna Macedo de Oliveira e Larissa Fostinone Locoselli. O objetivo do presente trabalho é viabilizar o diagnóstico das políticas de facto da UNILA, por meio da metodologia a seguir explicitada.

\section{Metodologia}

Esta pesquisa foi construída em conformidade à proposta analítica de Shohamy (2006), segundo a qual analisamos, por meio de dados e documentos institucionais, o tripé 
ensino-pesquisa-extensão, através do uso da metodologia quantitativa, com o intuito de observar como se evidencia o compromisso da instituição em relação ao bilinguismo para além do aspecto legislador.

Quanto ao "ensino", foram analisadas as bibliografias das disciplinas obrigatórias dos cursos de graduação, mestrado e especialização, e contabilizados os títulos em espanhol, português, inglês, francês e em outras línguas. A escolha destas categorias é facilmente explicada: como as línguas oficiais da instituição são o português e o espanhol, esperava-se que grande parte dos títulos sugeridos estivessem nessas línguas; consideramos também o fato de o inglês ser a língua predominante na produção do conhecimento científico, bem como, em certa medida, o francês, que além de ter grande representatividade no mundo acadêmico, é uma língua latina - e língua materna de vários estudantes da UNILA -; com a última categoria, buscávamos reconhecer a incidência de outras línguas nesse espaço.

Para essa tabulação, prezou-se o idioma das edições propostas nos Projetos Pedagógicos dos Cursos (PPCs). Dos 29 cursos de graduação da UNILA, foram considerados no estudo todos aqueles que tiveram o PPC aprovado até o ano 2016, razão pela qual os cursos de Ciências da Natureza - Biologia, Física e Química, Engenharia de Materiais e Engenharia Química não fazem parte de nosso escopo. Dos seis cursos de mestrado ofertados em 2016, apenas os Mestrados em Física Aplicada e em Literatura Comparada constam da análise, pois as bibliografias não foram disponibilizadas pela instituição. A também não disponibilidade dos PPCs do curso de Especialização em Educação Ambiental e do Programa de Residência Multiprofissional em Saúde da Família justifica a ausência desses dados na tabulação.

Já em relação à "pesquisa", foi verificado o número de projetos relacionados a Línguas no período 2010-2016 e suas respectivas subáreas. Quanto às ações de "extensão", foram computados os projetos dessa área ao longo do mesmo período e observado o ano de criação de cada um.

\section{Resultados}

\subsection{Ensino: bibliografias dos cursos de graduação, mestrado e especialização}

Contabilizamos, conforme a metodologia já explicitada, 9.230 textos referenciados nos PPCs dos cursos da UNILA. Buscamos identificar a quantidade de referências na língua espanhola, francesa, inglesa, portuguesa e em outras línguas. A partir da análise deste total geral, constatamos a prevalência de textos indicados em português (78\%), número este 
distante das línguas que seguem o ranking: o inglês (11\%) e o espanhol (10,9\%). A língua francesa teve uma presença bastante reduzida diante do total contabilizado, representando apenas $0,13 \%$.

Tabela 1 - Relação do total de textos de cada idioma referenciados nas bibliografias dos cursos da UNILA por nível acadêmico

\begin{tabular}{lrrrrrr}
\hline $\begin{array}{l}\text { NÍVEL } \\
\text { ACADÊMICO }\end{array}$ & ESPANHOL & FRANCÊS & INGLÊS & PORTUGUÊS & $\begin{array}{r}\text { OUTRAS } \\
\text { LÍNGUAS }\end{array}$ & TOTAL \\
\hline Graduação & 906 & 11 & 840 & 6708 & 0 & $\mathbf{8 . 4 6 4}$ \\
Mestrado & 76 & 1 & 166 & 265 & 0 & $\mathbf{5 0 8}$ \\
Especialização & 23 & 0 & 9 & 226 & 0 & $\mathbf{2 5 8}$ \\
TOTAL & $(10,9 \%) \mathbf{1 . 0 0 5}$ & $(0,13 \%) \mathbf{1 2}$ & $(11 \%) \mathbf{1 . 0 1 5}$ & $(78 \%) \mathbf{7 . 1 9 9}$ & $(0 \%) \mathbf{0}$ & $(100 \%) \mathbf{9 . 2 3 0}$ \\
\hline
\end{tabular}

Dos cursos de graduação, foram avaliados 8.464 textos no que concerne às suas bibliografias - obrigatória e complementar - das disciplinas obrigatórias específicas de cada curso $^{3}$. Destes, $79,3 \%$ estão escritos em português, 10,7\% em espanhol, 9,9\% em inglês, e apenas $0,1 \%$ em francês. Esses números evidenciam uma imensa disparidade com respeito ao espaço ocupado pelas línguas portuguesa e espanhola nas bibliografias utilizadas na instituição. A proximidade das porcentagens de textos em espanhol e em inglês reforça ainda mais o status inferior atribuído à língua espanhola, apesar dela ser uma das línguas oficiais da UNILA.

Do total de 508 textos dos cursos de mestrado, 52,2\% dos títulos aparecem em português, $15 \%$ em espanhol, $32,7 \%$ em inglês, e $0,2 \%$ em francês. Percebe-se que o português também é a língua mais presente nas bibliografias deste nível acadêmico. Além disso, o grande número de textos em inglês, o dobro de títulos verificados em espanhol, reafirma a valorização de produções nessa língua no meio acadêmico.

Os cursos de especialização contam com 258 textos nas disciplinas obrigatórias, sendo 87,6\% em português, 8,9\% em espanhol e 3,5\% em inglês. Aqui novamente a presença do português é majoritária. Contudo, ao contrário do que se observava para o nível de mestrado, o número de títulos em espanhol é superior ao de títulos em inglês nos cursos de especialização, embora ambos apresentem uma porcentagem pouco relevante no todo. Uma possível explicação para esse resultado, acreditamos, pode advir do fato de que a maioria dos estudantes de especialização são oriundos da cidade de Foz do Iguaçu e região, um perfil não exatamente idêntico ao verificado nos cursos de pós-graduação stricto sensu da UNILA.

\footnotetext{
${ }^{3}$ As disciplinas do Ciclo Comum de Estudos (Fundamentos da América Latina I, II e III, Língua Adicional, Introdução ao Pensamento Científico e Ética e Ciência) e Inglês Instrumental foram desconsideradas na tabulação dos dados aqui apresentados.
} 
Em suma, observamos que a língua inglesa, com exceção dos cursos de especialização e, notadamente, nos cursos de mestrado da universidade, goza de um status maior em comparação com o da língua espanhola. Constatamos também que a língua portuguesa é referenciada massivamente nos três níveis acadêmicos, enquanto que a língua francesa conta com uma porcentagem mínima no total de referências. Ademais, não identificamos nenhum texto referenciado escrito em outra língua além das quatro citadas.

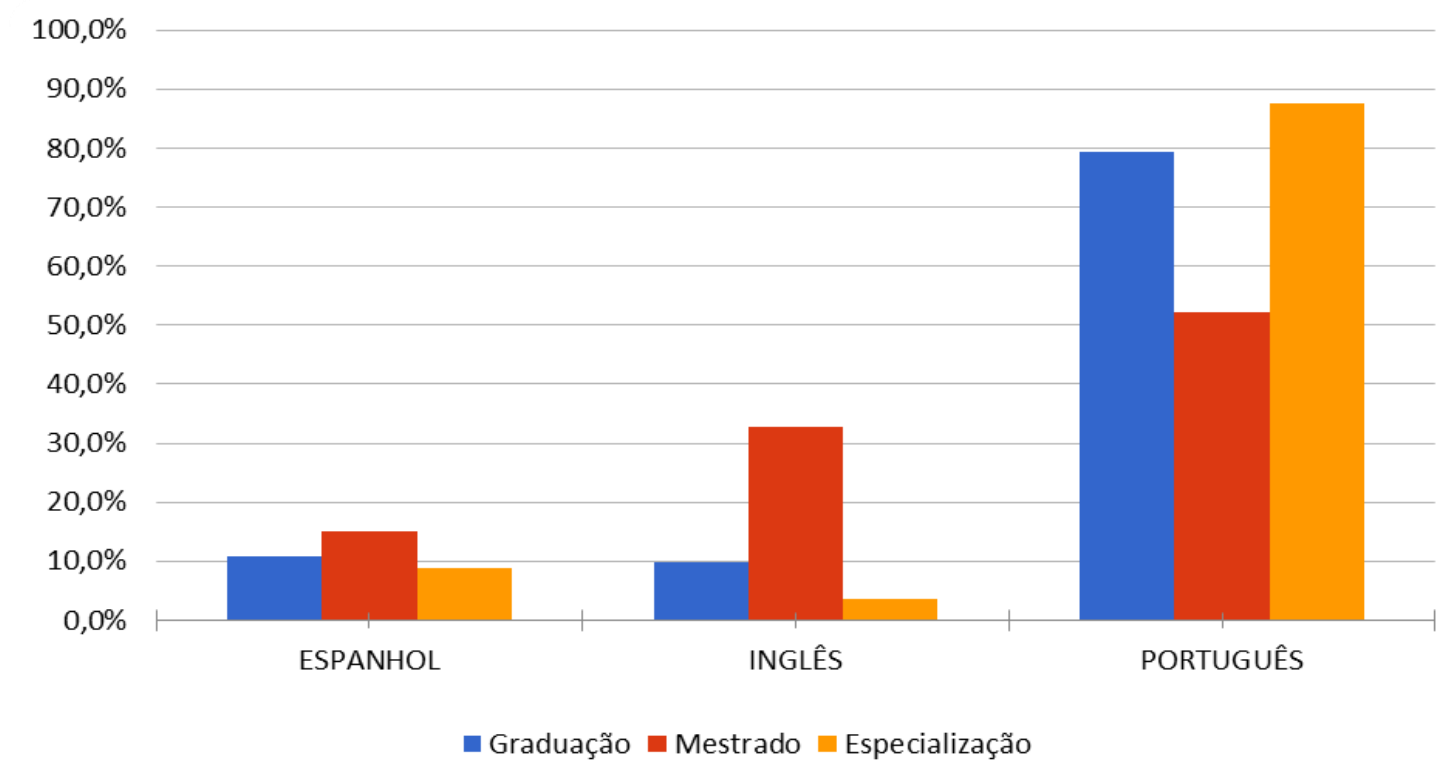

Gráfico 1 - Relação entre o percentual de textos referenciados nas bibliografias das disciplinas obrigatórias dos cursos de graduação, mestrado e especialização da UNILA por idioma e nível acadêmico segundo os PPCs

O gráfico acima é capaz de ilustrar que, apesar do bilinguismo (português-espanhol) ser um princípio filosófico-metodológico da UNILA, sua concretude, em termos de equiparação do lugar dessas duas línguas, no que tange ao arcabouço teórico das práticas de ensino da instituição, não se dá de forma eficiente.

\subsubsection{Um olhar aprofundado: cursos de graduação}

Apesar de os PPCs não necessariamente significarem o cotidiano dos cursos de graduação, eles representam os moldes nos quais os cursos foram pensados e projetados, por isso é interessante analisar como as línguas estão representadas ao longo das sugestões de bibliografia. A tabela 2 mostra, em números, a grande dificuldade em se instituir o bilinguismo nas práticas de ensino nas graduações da UNILA.

Absolutamente todos os cursos têm como referência a maioria dos textos em português, como já se indicava no tópico anterior. Há, inclusive, casos extremos de cursos que 
contam com mais de $90 \%$ de seus textos em português, como são exemplos os cursos de Arquitetura e Urbanismo, Matemática - Licenciatura, Medicina e Serviço Social.

Interessante igualmente observar apesar de nenhum curso ter alcançado o percentual de $30 \%$ de textos em espanhol, quatro cursos - Biotecnologia, Ciências Biológicas - Ecologia e Biodiversidade, Engenharia Física e Música - ultrapassaram esse quantitativo em relação aos textos em inglês. A baixa incidência de textos em espanhol é instigante, considerando que 7 dos 26 cursos contabilizados não têm nem mesmo 3,5\% de seus textos nesta língua.

Tabela 2 - Relação curso/percentual de textos referenciados por idioma

\begin{tabular}{|c|c|c|c|c|}
\hline CURSO & ESPANHOL & FRANCÊS & INGLÊS & PORTUGUÊS \\
\hline Administração Pública e Políticas Públicas & $10,4 \%$ & $0,0 \%$ & $1,4 \%$ & $88,2 \%$ \\
\hline $\begin{array}{l}\text { Antropologia - Diversidade Cultural Latino- } \\
\text { Americana }\end{array}$ & $26,4 \%$ & $0,0 \%$ & $1,8 \%$ & $71,8 \%$ \\
\hline Arquitetura e Urbanismo & $2,1 \%$ & $0,5 \%$ & $0,2 \%$ & $97,4 \%$ \\
\hline Biotecnologia & $3,1 \%$ & $0,0 \%$ & $35,3 \%$ & $61,6 \%$ \\
\hline $\begin{array}{l}\text { Ciência Política e Sociologia - Sociedade, Estado e } \\
\text { Política na América Latina }\end{array}$ & $6,7 \%$ & $0,0 \%$ & $3,4 \%$ & $89,9 \%$ \\
\hline Ciências Biológicas - Ecologia e Biodiversidade & $10,2 \%$ & $0,0 \%$ & $33,9 \%$ & $55,9 \%$ \\
\hline $\begin{array}{l}\text { Ciências Econômicas - Economia, Integração e } \\
\text { Desenvolvimento }\end{array}$ & $6,1 \%$ & $0,0 \%$ & $11,2 \%$ & $82,7 \%$ \\
\hline Cinema e Audiovisual & $27,6 \%$ & $0,0 \%$ & $6,5 \%$ & $65,8 \%$ \\
\hline Desenvolvimento Rural e Segurança Alimentar & $11,5 \%$ & $0,0 \%$ & $0,0 \%$ & $88,5 \%$ \\
\hline Engenharia Civil de Infraestrutura & $17,3 \%$ & $0,0 \%$ & $4,1 \%$ & $78,5 \%$ \\
\hline Engenharia de Energias Renováveis & $7,7 \%$ & $0,0 \%$ & $14,5 \%$ & $77,8 \%$ \\
\hline Engenharia Física & $2,6 \%$ & $0,0 \%$ & $31,3 \%$ & $66,2 \%$ \\
\hline Filosofia - Licenciatura & $19,1 \%$ & $0,0 \%$ & $0,4 \%$ & $80,5 \%$ \\
\hline Geografia - Bacharelado & & $0,4 \%$ & $15,7 \%$ & $77,9 \%$ \\
\hline Geografia - Licenciatura & $\begin{array}{l}6,0 \% \\
5,4 \%\end{array}$ & $0,4 \%$ & $6,5 \%$ & $87,8 \%$ \\
\hline História - América Latina & $23,4 \%$ & $0,0 \%$ & $7,2 \%$ & $69,4 \%$ \\
\hline História - Licenciatura & $17,2 \%$ & $0,4 \%$ & $1,6 \%$ & $80,7 \%$ \\
\hline Letras - Arte e Mediação Cultural & $37,5 \%$ & $0,6 \%$ & $1,0 \%$ & $60,9 \%$ \\
\hline \multicolumn{5}{|l|}{ Letras - Português e Espanhol como Línguas } \\
\hline Estrangeiras & $26,0 \%$ & $1,3 \%$ & $4,0 \%$ & $68,7 \%$ \\
\hline Matemática - Licenciatura & $0,0 \%$ & $0,0 \%$ & $6,6 \%$ & $93,4 \%$ \\
\hline
\end{tabular}




$\begin{array}{lcccc}\text { Medicina } & 3,3 \% & 0,0 \% & 2,0 \% & 96,5 \% \\ \text { Música } & 1,5 \% & 0,0 \% & 31,5 \% & 53,2 \% \\ \text { Química - Licenciatura } & 15,3 \% & 0,0 \% & 14,2 \% & 83,6 \% \\ \text { Relações Internacionais e Integração } & 2,1 \% & 0,0 \% & 9,7 \% & 73,3 \% \\ \text { Saúde Coletiva } & 9,7 \% & 0,0 \% & 3,0 \% & 87,3 \% \\ \text { Serviço Social } & 8,4 \% & 0,0 \% & 0,0 \% & 91,6 \%\end{array}$

Diante desse cenário, não podemos deixar de apontar que os cursos que mais apresentaram bibliografia em inglês são das áreas de Ciências Exatas e Ciências Biológicas, enquanto que os que mais apresentaram bibliografia em espanhol pertencem à área de Ciências Humanas. À primeira vista, é possível identificar a influência da produção científica a nível global na elaboração dos cursos da UNILA e, mesmo que esta universidade tenha como vocação a integração latino-americana, ela não deixa de estar submetida à certa lógica de funcionamento perpetuada no meio acadêmico-científico, cuja produção e circulação, como se sabe, dá-se majoritariamente em/de/para a língua inglesa.

\subsection{Pesquisa: projetos de pesquisa vinculados a Línguas no período 2010-2016}

Dos 324 projetos de pesquisa propostos no período 2010-2016 na UNILA, apenas 16 relacionam-se à questão da língua, representando 4,94\% do total de projetos de pesquisa da universidade. Destes, somente um não tem origem no Instituto Latino-Americano de Arte, Cultura e História (ILAACH), mas sim no Instituto Latino-Americano de Economia, Sociedade e Política (ILAESP). Tendo em vista que as pesquisas são sempre vinculadas a um instituto $^{4}$ ou à própria instituição, é importante frisar que nenhum projeto surgiu de demandas institucionais, ou seja, nenhum dos projetos cadastrados sobre essa temática é resultado de uma iniciativa da instituição ou de uma solicitação desta aos docentes.

Apesar de a UNILA existir desde 2010, apenas em 2013 foi proposto o primeiro projeto de pesquisa sobre Línguas de que temos registro por meio das informações disponíveis no site da instituição. Em 2014 foram propostos mais 4, em 2015, mais 7 e em 2016, mais 4. O maior interesse destas pesquisas é a relação entre Língua e Educação, com 10

\footnotetext{
${ }^{4}$ Os cursos da UNILA estão vinculados a institutos que, como unidades acadêmicas, realizam a gestão administrativa do ensino, da pesquisa e da extensão.
} 
projetos, seguido pela área de Linguística, com 3 projetos, de Política Linguística com 2 e, por fim, de Literatura, com apenas um. É o que se observa no gráfico abaixo:

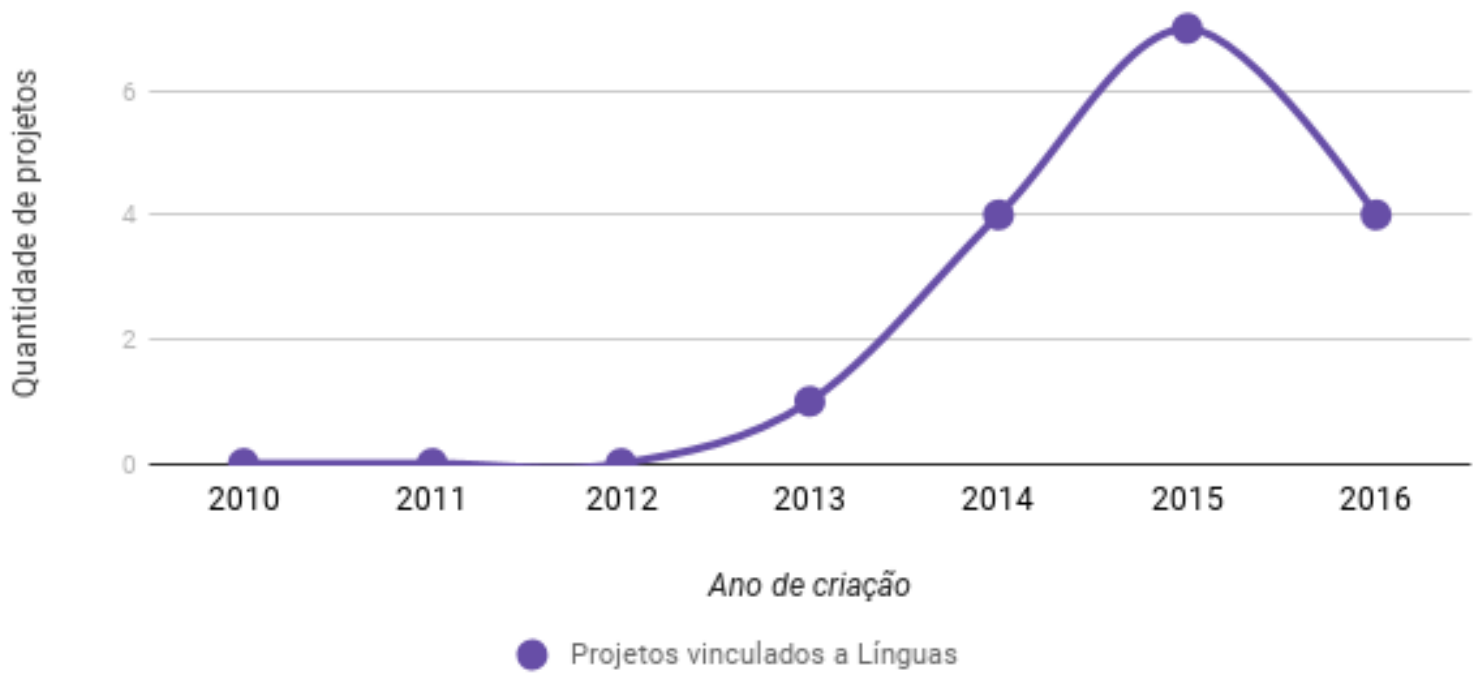

Gráfico 2 - Relação entre a quantidade de projetos de pesquisa da UNILA vinculados a Línguas por ano de criação

Podemos notar que a ausência de proposição de projetos nessa área pela própria UNILA reflete o distanciamento da instituição de uma problemática muito presente na constituição desta universidade. Em contrapartida, a existência de novos projetos a partir de um determinado momento reflete o interesse da própria comunidade acadêmica em relação ao tema, quando observamos o salto de 1 projeto em 2013 para 16 em 2016.

\subsection{Extensão: ações de extensão vinculadas a Línguas no período 2010-2016}

Foram propostas na UNILA 55 ações de extensão vinculadas ao tema "Línguas" no período de 2010 a 2016, o que representa 10,25\% do total de 573 ações da instituição. Conforme o gráfico 3, é possível identificar que no primeiro ano da universidade não houve nenhuma ação desta temática, enquanto que no ano seguinte constavam registradas 13 ações. O total de ações se manteve em torno desse número até o ano de 2014, quando nenhuma nova ação foi proposta, e voltou a subir em 2015, com 4 novos projetos. O ano de 2016 foi o mais profícuo para essa temática, contando com 15 novas ações.

Fica evidente, portanto, que apesar de ter existido uma queda de novas proposições no período 2013-2014 - contexto de pós-greve, quando em 2013 não foi aberta nenhuma vaga para ingressantes -, a UNILA manteve um número equilibrado de ações de extensão relacionadas a Línguas ao longo de sua existência. 
RELACult - Revista Latino-Americana de Estudos em Cultura e Sociedade

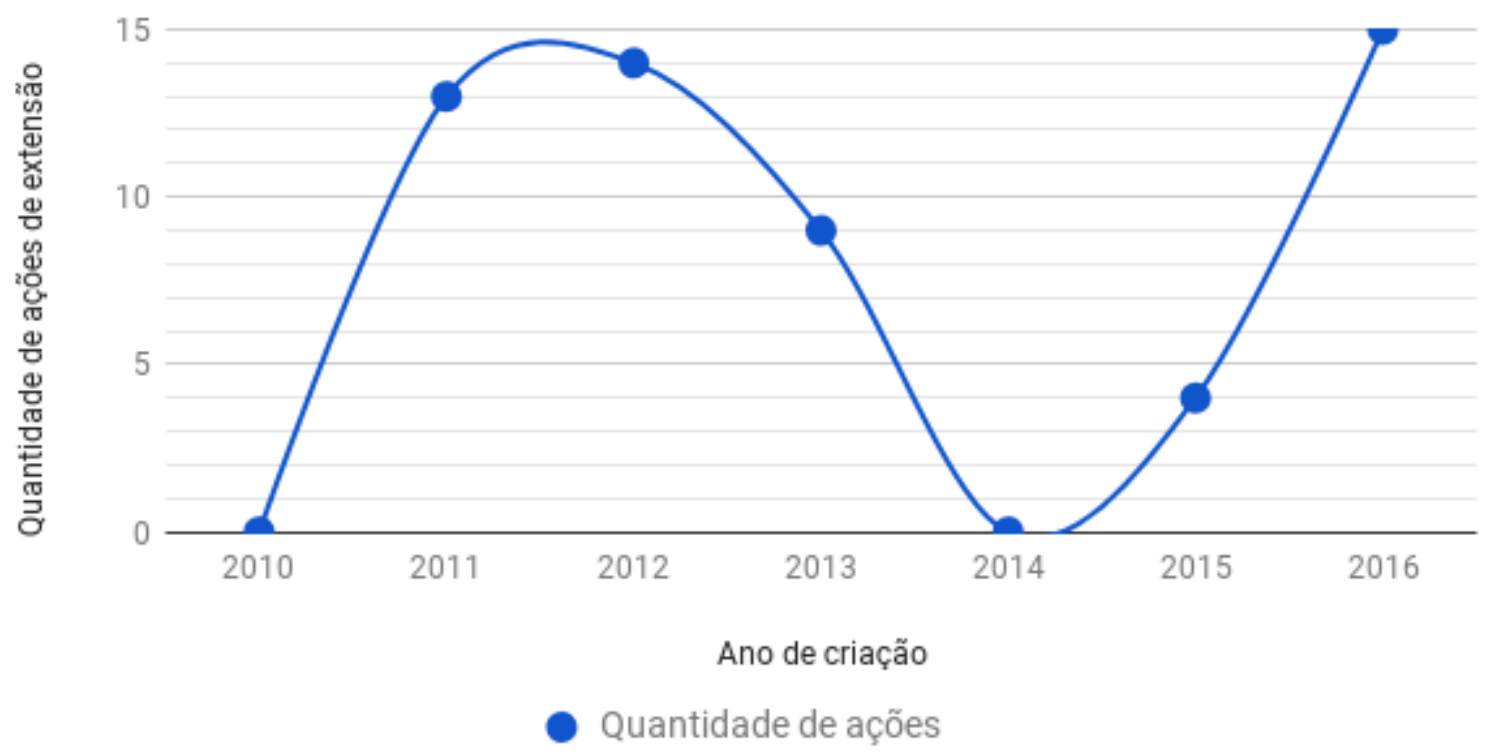

Gráfico 3 - Relação entre o ano de criação e a quantidade de ações de extensão da UNILA vinculados à Línguas

Considerando o fato de que as ações de extensão procuram atender as demandas da comunidade externa, e também que a UNILA está inserida em contexto fronteiriço, é interessante observar a finalidade dos projetos registrados ao longo desse tempo. $\mathrm{O}$ foco no português e/ou espanhol é central na maioria das propostas, ao mesmo tempo, o interesse nas línguas nativas - como o quéchua e o guarani - é igualmente muito grande. A língua inglesa também é alvo de muitas das ações, uma vez que esta é uma língua hegemônica e exerce forte influência tanto dentro da academia, quanto fora dela. Outros temas, como tradução e diversidade linguística, também foram alvos das ações de extensão da UNILA, apesar de serem abordados com menor frequência.

O interesse constante pela questão da Língua e a demanda por trabalhos que envolvam as duas línguas oficiais da UNILA condizem com a realidade na qual esta universidade está inserida. Embora o número de ações de extensão não seja muito grande, é de se valorizar o fato de que muitos desses projetos se mantiveram existindo ao longo dos anos, o que traduz a grande requisição de se aprofundar esta temática.

\section{Considerações Finais}

Observar os títulos escolhidos como bibliografias das disciplinas obrigatórias dos cursos da UNILA evidenciou que atribuir o mesmo status para as duas línguas ditas oficiais, o espanhol e o português, é um grande desafio, ainda não afrontado pela instituição. Ficou ainda mais nítida a maior importância dada à língua portuguesa em relação à espanhola, situação detalhada por Carvalho em seu estudo de 2012, antes aludido, e que se mantém vigente até hoje. Ao mesmo tempo, a valorização da língua inglesa mostrou-se como um sintoma, que é 
tão comum à maioria das universidades latino-americanas, de alinhamento à produção hegemônica de ciência. Essas características revelam as dificuldades em valorizar produções acadêmicas que partam da América Latina, tal como propõe o projeto desta universidade.

Quanto aos projetos de pesquisa, representando menos de $5 \%$ do total de projetos da universidade, a área de Línguas é mais estudada quando relacionada à educação. Este grande interesse condiz com as demandas do contexto fronteiriço e multilíngue, no qual a UNILA está situada e edificada, pois se coloca em evidência a necessidade de compreender a complexidade envolvida nas realidades multilíngues para o processo de ensino-aprendizagem.

No que concerne às ações de extensão, a UNILA mostrou-se consistente em relação à sua proposta latino-americanista, pois, apesar de representar apenas 10,25\% do total de ações, o interesse constante na criação de propostas que levem à comunidade externa o tema das línguas - na maioria das vezes no formato de cursos de idiomas -, demonstra, de certa forma, uma busca por concretizar o princípio do bilinguismo e do multilinguismo neste âmbito.

Evidencia-se, assim, que a complexidade em se constituir, solidamente, o princípio do bilinguismo ultrapassa o espaço da sala de aula, e atinge todos os âmbitos da universidade. A ausência de uma definição clara desse princípio na documentação institucional, como apontava Oliveira em sua comunicação de 2016, é mostra dessa dificuldade e da incerteza, por parte da UNILA, de que bilinguismo exatamente se pretende concretizar. A grande presença do português na constituição do tripé ensino-pesquisa-extensão é reflexo do fato de a UNILA, apesar de sua vocação, ser uma universidade brasileira em território brasileiro.

Diante desse contexto, é plasmada a hipótese de nossa pesquisa: existem dificuldades - que perpassam os espaços institucionais, acadêmicos e, consequentemente, pessoais - ao longo do processo de produção do conhecimento a partir da UNILA devido a barreiras linguísticas que não foram dirimidas pelas políticas propostas pela universidade. A maior contribuição do presente estudo é, portanto, servir ao embasamento de uma pesquisa que propõe alinhar-se ao desenvolvimento de um dos princípios filosófico-metodológicos que constitui o diferencial desta instituição.

\section{Referências}

BERGER, Isis Ribeiro. Gestão do multi/plurilinguismo em escolas brasileiras na fronteira Brasil - Paraguai: um olhar a partir do Observatório da Educação na Fronteira. 2015. 298f. Tese (Doutorado em Linguística) - Programa de Pós-Graduação em Linguística, Universidade Federal de Santa Catarina, Florianópolis, 2015. 
CARVALHO, Simone da Costa. As relações de status entre as línguas na implementação em processo de uma proposta acadêmica bilíngue em um cenário institucional multilíngue latino-americano. 2012. 165f. Dissertação (Mestrado em Linguística Aplicada) - Programa de Pós-Graduação em Letras, Universidade Federal do Rio Grande do Sul, Instituto de Letras, Porto Alegre, 2012.

OLIVEIRA, Bruna Macedo. Las políticas de gestión de las lenguas en UNILA: un estudio de caso a partir de los documentos oficiales de la institución. In: Tercer CIPLOM/EAPLOM. Florianópolis, 2016.

SHOHAMY, Elana. Lenguage Policy: hidden agendas and new approaches. NY: Routledge, 2006. [apud BERGER, Isis Ribeiro, 2015.]

UNIVERSIDADE FEDERAL DA INTEGRAÇÃO LATINO-AMERICANA (UNILA). Plano de Desenvolvimento Institucional (PDI) 2013-2017. Foz do Iguaçu, 2013, p. 1-71. Disponível em: <https://www.unila.edu.br/sites/default/files/files/PDI\%20UNILA\%2020132017.pdf>. Consultado em: 22/02/2016. 